\title{
O lobby como estratégia criativa de oposição
}

\section{Lobbying as a creative opposition strategy}

El lobby como estrategia creativa de oposición

\section{Asdrúbal Borges Formiga Sobrinho}

- Doutor em Psicologia pelo Instituto de Psicologia da Universidade de Brasília (UnB)

- Mestre em Comunicação Social pela Faculdade de Comunicação da UnB

- Graduado em Publicidade e Propaganda pela UnB

- Organizador do livro Personagens da propaganda brasileira - Vol. 1.

- Professor adjunto do curso de Comunicação Social da UnB

- Professor e assessor pedagógico do curso de Comunicação Social da Universidade Católica de Brasília (UCB) de 2001 a 2009

- asdru_bal@uol.com.br 
Este artigo aborda a semiose de um conceito empregado na comunicação de uma organização. Baseia-se no modelo de Goodall Jr., Eisenberg e Trethewey (2010) que apresenta a comunicação diante da dicotomia entre criatividade e sujeição (Scroferneker, 2006); e se enquadra na perspectiva interpretativa, que aborda organizações como culturas (Kunsch, 2009). A interpretação se baseia em conceitos como texto e não-texto (Lotman, 1978, Machado, 2003). Os resultados indicam o potencial de ressignificação de um conceito no contexto externo à organização e ações adaptativas da mesma.

PALAVRAS-CHAVE: IMAGEM INSTITUCIONAL • CRIATIVIDADE • CULTURA ORGANIZACIONAL • TEXTO • LOBBY

\section{Abstract}

This article addresses the semiotics of a concept used for the communication of an organization. It is based on the model by Goodall Jr., Eisenberg and Trethewey (2010), which presents communication in the light of the dichotomy between creativity and subjection (Scroferneker, 2006); and it is related to the interpretive perspective that addresses the organizations as cultures (Kunsch, 2009). The interpretation is based on concepts such as text and non-text (Lotman, 1978; Machado, 2003). The results show the re-signification potential of a concept in a context that is external to the organization and its adaptation actions.

KEYWORDS: INSTITUTIONAL IMAGE • CREATIVITY • ORGANIZATIONAL CULTURE • TEXT • LOBBY

\section{Resumen}

El artículo trata de la semiosis de un concepto empleado en la comunicación de una organización. Se basa en el modelo de Goodall Jr., Eisenberg y Trethewey (2010) que muestra la comunicación ante la dicotomía entre creatividad y sujeción (Scroferneker, 2006); y se enmarca en la perspectiva interpretativa, que aborda las organizaciones como culturas (Kunsch, 2009). La interpretación se basa en conceptos como texto y no texto (Lotman, 1978, Machado, 2003). Los resultados indican el potencial de resignificación de un concepto en el contexto externo a la organización y acciones adaptativas.

PALABRAS CLAVE: IMAGEN INSTITUCIONAL • CREATIVIDAD • CULTURA ORGANIZACIONAL • TEXTO • LOBBY 
- m nossa cultura, criatividade é um termo sedutor, muito associado a ori- ginalidade e referente tanto aos inventos, quanto ao estabelecimento de novas relações (Novaes, 1972) entre palavras e imagens, por exemplo.

O termo também está associado ao responsável pela criação e envolve seu posicionamento, entendido como "o processo discursivo em que pessoas estão localizadas em comunicações como observavelmente e subjetivamente participantes em mensagens produzidas conjuntamente" (Davies; Harre, 1997, p. 46). Dessa forma, envolve desde conhecimentos a atitudes morais e emocionais dos participantes do processo criativo, inclusive na semiose, entendida como "processo de transmissão e transformação de mensagens" (Machado, 2003 , p. 52) cujo resultado pode levar as pessoas a compreender ou mesmo elaborar conteúdos de outra forma.

A compreensão ou resposta à mensagem criativa também envolve valores, que se baseiam condição humana (Bain; Kashima; Haslam, 2006) e são partilhados culturalmente. Tal caráter cultural contribui para os valores serem estabelecidos também pelo impacto das emoções sobre as crenças. Oriundas de conhecimentos e práticas religiosas (Weber, 1998), as crenças constituem verdadeiras "regras para ações" (Rosa, 2007, p. 311), cuja diversidade ou cuja interpretação pode diversificar condutas, uma vez que a interpretação se baseia também em emoções agregadoras de importância valorativa aos significados.

Além de associado ao novo e à pessoa considerada criativa, o termo criatividade também está relacionado ao processo de criação e ao produto criado (Novaes, 1972). Para discutirmos a classificação criativa de ambos, faremos uma abordagem da semiose de um determinado "discurso organizacional" (Halliday, 2009, p. 46) como efeito da interação com diferentes públicos. A proposta baseia-se no fato de os profissionais responsáveis pela criação da campanha institucional já terem consagrada sua classificação como criativos, sendo deles já esperados e até exigidos produtos criativos. Baseia-se também em nossa intenção de demonstrar outras facetas da criatividade aplicadas aos diferentes integrantes de um processo comunicativo. Nele são consideradas atitudes e ações geradoras e atenuantes de uma crise desencadeada pela interpretação de uma propaganda.

Antes de tratarmos do processo, entretanto, fazemos ressalvas diante de possíveis estereotipias da pessoa criativa, já que é possível "ser criativo através de processo interno continuadamente em ação, nem sempre observável, ou até, em certos casos, fundamentalmente inobservado e não identificado como tal" (Novaes, 1972, p. 33). Além do mais, embora a apresentação de inovações ou originalidades tenda a incomodar indivíduos e organizações mantenedores do status quo, nem sempre ser criativo deve ser sinônimo de ser subversivo, pois criativos também podem produzir mensagens consonantes com o status quo. Podem também, ao contrariá-lo, repensar suas estratégias, considerando que a negociação de significados depende de múltiplos fatores contextuais, alguns dos quais serão exemplificados nas próximas seções. 


\section{TENSÕES CRIATIVAS}

Nesta seção, abordamos a criatividade aplicada à retórica organizacional e expressa numa propaganda, com base na perspectiva interpretativa, que aborda a cultura organizacional como uma rede de significados (Kunsch, 2009), para tratar da semiose de um conceito de comunicação. A abordagem parte da seguinte pergunta de pesquisa: embora se possa fazer o melhor uso possível dos recursos de comunicação e monitorar a recepção de discursos organizacionais no âmbito externo (Iasbeck, 2009) ou interno (Roman, 2009), haveria criatividade ou sentido estratégico suficientes para controlar uma imagem institucional ou isso não passaria de uma meta?

Inicialmente, cabe consideramos que, por um lado, os públicos concebem a imagem de uma organização a partir de modelos mentais pré-existentes e decorrentes do próprio convívio social. Por outro lado, imagens mentais estão sujeitas a reconstruções progressivas orientadas também pela comunicação e, em nosso exemplo, pela propaganda. Tal gênero de linguagem possui um papel fundamental na produção de discursos, aqui denominadas textos (Lotman, 1978), pelo fato de envolverem combinações entre códigos verbais e visuais. A finalidade primordial dos discursos desse gênero, por sua vez, divide-se em estabelecer, modificar e controlar as identidades organizacionais. Isso porque indivíduos possuem múltiplas identidades, relacionadas com diferentes fatores como classe social, gênero, ocupação etc. (Hall, 1992) e tal multiplicidade também se aplica às identidades organizacionais, já que a propaganda busca personificar organizações ao trabalhar seus posicionamentos nas interações e tensões diante da concorrência.

Entretanto, mesmo não sendo apenas no âmbito interorganizacional que determinadas tensões emergem, é nele que abordaremos uma reação ao lançamento da campanha baseada no conceito "Decida pelo três", assinada pelo Banco Beta. O roteiro da principal peça da campanha é apresentado a seguir.

\begin{tabular}{|r|l|}
\hline Trilha (BG): & Rock com acordes de guitarra em ritmo mais lento. \\
\hline $\begin{array}{r}\text { Locução } \\
\text { em off: }\end{array}$ & $\begin{array}{l}\text { No princípio decidiu-se que seria arredondada, depois decidiu-se que teria terra firme } \\
\text { e céu azul, com nuvens brancas durante o dia, e também decidiu-se que teria água } \\
\text { e que ela estaria nos mares e rios. Decidiu-se que teria o ar e com ele os ventos. } \\
\text { Decidiu-se que teria plantas e que teria animais. Decidiu-se que os peixes ficariam } \\
\text { na água e as aves, nos céus. Decidiu-se que teria pessoas e que nós dependeríamos } \\
\text { de tudo isso pra viver. Bom, então decidiu-se que a partir daí as decisões seriam to- } \\
\text { madas por nós. As opiniões foram as mais diversas e cada um tomou suas decisões. } \\
\text { Teve gente que decidiu ganhar o mar. Teve gente que decidiu ganhar o céu. Teve até } \\
\text { quem decidisse ganhar o espaço. Alguns decidiram liderar e decisões importantes to- } \\
\text { madas por eles mudaram o rumo do planeta. Às vezes para pior, às vezes para melhor. } \\
\text { E como as decisões nos ocupavam muito, demoramos a perceber que são elas que } \\
\text { podem decidir o nosso futuro. E aí decidimos fazer algo para cuidar de tudo isso que } \\
\text { foi, está sendo ou ainda vai ser decidido daqui para frente. }\end{array}$ \\
\hline
\end{tabular}




\begin{tabular}{|c|c|}
\hline Imagem: & $\begin{array}{l}\text { Vários quadros com as cenas a seguir. Parte do planeta girando com a luz do sol } \\
\text { ao fundo. Erupção vulcânica. Fogo. Floresta com dinossauros e cometa. Montanhas } \\
\text { passando rapidamente. Planeta Terra. Floresta. Céu com nuvens. Grandes ondas. Rio } \\
\text { Amazonas. Céu nublado e escuro. Folha caindo na água. Brotos crescendo. Onça } \\
\text { descansando preguiçosamente em cima de uma árvore. Peixes azuis e amarelos na- } \\
\text { dando. Gaivotas voando ao pôr do sol. Mulher na praia. Homem negro com rastafári } \\
\text { sorrindo. Menina com céu e nuvens ao fundo. Cadeia do DNA. Árvore frondosa no } \\
\text { campo. Imagens que se sucedem aceleradas cidades, aviões, planeta, homem abrin- } \\
\text { do uma porta no escuro. Homem com figura de interrogação ao fundo. Três homens } \\
\text { se divertindo e cantando. Mulher com uma figura que classifica partes do cérebro } \\
\text { e seus possíveis pensamentos. Três crianças sorrindo. Amigos (negro, moreno e } \\
\text { loiro) se abraçando. Caravelas. Primeiros aviões fazendo acrobacias. Astronautas e } \\
\text { foguetes. Homem com megafone. Quadros em preto e branco com aviões de guerra, } \\
\text { seres humanos, um menino com olhar de surpresa e soldados marchando. Cenas de } \\
\text { bombas, acidentes naturais e catástrofes, fumaça de fábrica. Cenas da quebra do } \\
\text { muro de Berlim. Rostos de Gandhi e Betinho. Rosa desenhada. Imagem de uma TV. } \\
\text { Idoso no campo. Crianças em sala de aula aprendendo sobre os dinossauros. Cidade } \\
\text { crescendo. Criança com animal no colo, demonstrando cuidado. Casais namorando. } \\
\text { Figura de uma grávida, casamento. }\end{array}$ \\
\hline $\begin{aligned} \text { Locução } \\
\text { em off: }\end{aligned}$ & $\begin{array}{l}\text { A gente decidiu pelo três e queremos convidar você a tomar essa decisão com a } \\
\text { gente. Significa ter pelo menos três atitudes por dia, pensando na sustentabilidade } \\
\text { do planeta. Pode ser apagar a luz, fechar a torneira e ensinar alguém. Três. Pode } \\
\text { ser plantar uma árvore, catar uma latinha do chão e agir com ética. Três. Pode ser } \\
\text { tomar um banho mais curto, respeitar as diferenças e usar a escada. Três. Apenas } \\
\text { três. Em todo lugar que você vir esse número, vai saber que ali existe uma forma } \\
\text { de você tomar essa decisão para cuidar do planeta, das pessoas e do país em que } \\
\text { a gente vive. Três. }\end{array}$ \\
\hline Imagem: & $\begin{array}{l}\text { Rapaz mostrando três dedos. Cenas de crianças de diferentes etnias. Homem na ca- } \\
\text { deira de rodas. Praia com o numero três escrito na areia. Homem com regador. Mão } \\
\text { com objeto que lembra o planeta. Lâmpada. Torneira. Mulher mostrando o número } \\
\text { três com as mãos e sorrindo. Criança catando uma latinha do chão e jogando na lixei- } \\
\text { ra. Pessoa andando sobre uma linha. Crianças numa escada que mostram o número } \\
\text { três. Homem negro e imagem de gotas de água subindo. Pessoas caminhando com } \\
\text { roupa de trabalho. Criança subindo em árvore. Mulher mostrando o número três. Cata- } \\
\text { vento. Número três. Homem que decide e alegre cruza uma linha desenhada no chão. } \\
\text { Planeta terra. Pessoas sorrindo, parecendo felizes. Três ovos no ninho. Bebê. Três } \\
\text { enfermeiras de diferentes etnias. Jovem sorrindo. Três crianças brincando. Menino } \\
\text { oriental. Três amigos abraçados caminhando. }\end{array}$ \\
\hline Lettering: & $\begin{array}{l}\text { [bancobeta].com.br/sustentabilidade e Conheça a Agenda } 21 \text { em fundo azul. } \\
\text { Agenda 21. } 2+1=3 \text {. As letras são amarelas (cor do banco). }\end{array}$ \\
\hline $\begin{array}{r}\text { Locução } \\
\text { em off: }\end{array}$ & Pelo futuro do no nosso planeta e conte com o Banco. \\
\hline Lettering: & Todo seu. \\
\hline Imagem: & Marcas do governo federal. \\
\hline
\end{tabular}


O anunciante é uma importante organização estatal que tem a comunicação como forma de se legitimar no cenário de poder do governo e a referida propaganda como forma de confirmar que "comunicar-se bem é apresentar boas razões para atos e eventos passados, presentes e futuros" (Halliday, 2009 , p. 46). No enredo, isso ocorre quando se trata da história da Terra, da humanidade e do que pode ser feito agora para garantir um futuro melhor - ou mesmo algum futuro, em nível implícito - para a espécie e o Planeta. Trata-se de uma argumentação que dialoga com temas religiosos relacionados à criação e, não por acaso, baseada em princípios da remota propaganda religiosa (Domenach, 1955) também adotados na mercadológica, mas com a diferença de a religiosa mais prometer uma vida melhor em outro lugar e a mercadológica, na Terra. Num ponto intermediário, encontramos a propaganda institucional, cujo exemplo abordado sintetiza, no conceito "Decida pelo três", valores e crenças do público e objetivos organizacionais relacionados com diversas ações e programas do Banco Beta.

A referida propaganda institucional assume um caráter criativo, em princípio, por basear sua retórica em sentimentos e emoções (Novaes, 1972) e transcender o mero caráter informativo, num processo de "culturalização" (Machado, 2003, p. 142) vivenciado pelos diferentes polos da comunicação. Isso porque o que gera e diferencia o indivíduo, o processo e o produto criativo é sua biografia, ou seja, a importância do próprio indivíduo como constituinte e constituidor da cultura (Velho, 2004) e, conforme destacamos anteriormente, ao tratar de identidades, o mesmo se aplica às organizações personificadas pela propaganda.

Sua mensagem contraria uma tendência da comunicação empresarial vigente e também abordada por Iasbeck (2009), ao explicitar seus propósitos e estimular a interação. Talvez isso ocorra pelo fato de a propaganda ser assinada por uma organização estatal, embora esta dispute mercado com as privadas da categoria em patamares similares de investimento não apenas em comunicação. Tal disputa pode ter contribuído para a abordagem de temas como os relacionados a responsabilidade socioambiental, antigos integrantes do gênero institucional e misturados com recursos comumente utilizados no mercadológico, principalmente por organizações que precisam da propaganda institucional para corrigir sua imagem (Gracioso, 1995) ou prestar contas à sociedade, como as financeiras. Neste quesito, o gênero institucional também se mistura com o mercadológico, de caráter predominantemente persuasivo para fins comerciais e cuja retórica, que vem permeando os mais diferentes gêneros de discurso persuasivos (Reboul, 1996), tem recorrido a "atos de responsabilidade social, que se tornaram necessários para a manutenção do status de persona grata, almejado pelas organizações” (Halliday, 2009, p. 35). Portanto, principalmente pelo fato de a propaganda poder ser questionada, é preciso fazer com que os públicos creiam no que é dito ou os enunciados estejam de acordo com os valores e as crenças já partilhadas entre eles. 
E um questionamento realmente emergiu no período de veiculação da propaganda, quando o então senador piauiense Heráclito Fortes, do Partido dos Democratas (DEM), "subiu à tribuna para acusar o governo de estar, mais uma vez, usando o banco público para fazer propaganda subliminar em favor de um terceiro mandato do presidente Luiz Inácio Lula da Silva” (Scinocca; Filho, 2007). Por um lado, o político se baseou no fato de o teaser da campanha proporcionar esse tipo de interpretação, por ser ilustrado pelo cartaz exibido em paradas de ônibus - conforme imagem da figura 1, a seguir - e composto por diversas peças cujo destaque é o número 3, inclusive por uma camisa utilizada na ocasião pelo então senador paulista Eduardo Suplicy, do Partido dos Trabalhadores (PT). Por outro lado, ele aproveitou a oportunidade para oficializar um rumor também comentado pela imprensa, no ano 2007.

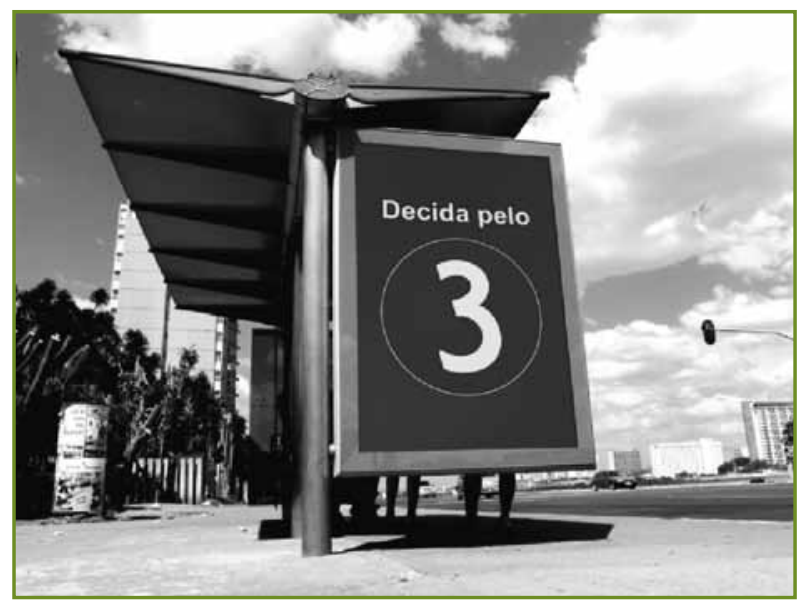

Figura 1 - Mídia outdoor

Com isso, o opositor passou a fazer lobby, compreendido como "exercício de influência, pressão e persuasão para obter atitude favorável em relação a um indivíduo ou instituição, de modo a efetivar um voto legislativo ou uma posição administrativa” (Rabaça; Barbosa, 2002, p. 348). A atividade também ocorre na iniciativa privada, mas diante do poder público encontra seu terreno mais fértil no âmbito legislativo. Embora já tenha sido regulamentada no Brasil, também é praticada informal e sutilmente por frequentadores do Congresso Nacional que buscam influenciar decisões de políticos; ou de forma evidente, por políticos que buscam influenciar as decisões de colegas ou até da população.

A ação do senador desencadeou uma crise que nos motivou a abordar o assunto, pois em contextos de crise a imagem institucional fica vulnerável e a comunicação é ainda mais necessária para recuperar, manter ou melhorar a reputação da organização. A tensão, portanto, não ocorreu ao acaso, mas foi estimulada pela retórica de um discurso sustentado em representações, que se 
baseiam em crenças e valores partilhados social e historicamente (Moscovici, 2003) e regidos culturalmente (Machado, 2003). Portanto, o discurso do político não constitui mera retórica.

O enredo da propaganda, outro importante mediador da tensão, também não é considerado mera retórica, o que poderia até mesmo inviabilizar seus efeitos (Halliday, 2009) ou o alcance de metas organizacionais previamente estabelecidas. Isso porque a campanha também contemplava o público interno, que aprovou as ações, principalmente após receber via e-mail um arquivo com o vídeo da referida propaganda, antes mesmo do público externo. Além do mais, não tivemos acesso a informações fundamentadas sobre sutis intenções eleitoreiras do anunciante ou dos criativos envolvidos com a produção da propaganda. Entretanto, pelo menos na retórica do opositor, a propaganda valeu-se de ambiguidades para, em nossas palavras, gerar uma atitude favorável entre os espectadores. Tal efeito é possível quando a mensagem está em consonância com as representações destes e é regida por elementos da cultura (Machado, 2003) brasileira e por particularidades da cultura organizacional (Kunsch, 2009) do anunciante. Cabe-nos, então, considerar como os limites encontrados por um texto assinado pela organização contribuíram para a semiose do próprio texto. Na seção seguinte, apresentamos um exemplo desse processo, já chamado também de ressignificação e culturalização.

\section{CRIATIVIDADES RESSIGNIFICADAS}

Limite pode ser compreendido como o elemento característico da oposição entre um texto e os signos que não compõem seu conjunto (Lotman, 1978), aqui chamados de não-textos. O limite é definido por marcas que caracterizam o texto a partir de sua função cultural ou de seu gênero - romance, filme, propaganda etc. É estabelecido, basicamente, por oposição com outros textos, mas sem impedimento de intercâmbios de signos entre eles. Esses intercâmbios permitem à significação mudar no processo de culturalização, cujo "resultado final é a transformação de um não-texto em texto” (Machado, 2003, p. 39).

No exemplo do qual tratamos, a oposição se estabeleceu no contexto de duas diferentes culturas organizacionais. Uma das organizações veiculou uma propaganda e um representante de outra, a oposição ao governo, aproveitou uma chance para se contrapor a um discurso que, embora consonante com as representações de preservação do meio ambiente e de responsabilidade social dos bancos, abria margem para um questionamento referente ao relacionamento entre tal organização e aquela gestão do governo federal. Tal situação nos levou a questionar quem realmente pode ser considerado criativo, pois, em princípio, seriam os responsáveis pela propaganda. Entretanto, ainda que de forma ambígua, um político teve concretizada numa ação de lobby uma atitude criativa, que 
representa uma resposta adequada a uma situação nova e uma resposta mais adequada e construtiva a uma situação antiga, devendo o indivíduo criador ser capaz de modificar seu comportamento em resposta a novas informações, desenvolver perspectivas a fim de progredir por si mesmo, de modo consistente, num estilo único de aprendizagem, estimulando a mudança, proporcionando oportunidades para transferir e aplicar o conhecimento às situações da realidade. (Novaes, 1972, p. 48-49)

Soma-se a isso o fato de que "administrar a dinâmica dessas relações [entre diferentes públicos] significa estar atento às possibilidades que se abrem e fecham constantemente no fluxo sistêmico das trocas informacionais" (Iasbeck, 2009, p. 16). Portanto, como consequência da atitude, a ação discursiva do político validou-se na semiose do conceito "Decida pelo três", cujo significado em discursos de outro gênero, como o jornalístico, constrangeu o proferido pela organização bancária estatal. Esse resultado deve-se ao fato de o discurso, inicialmente, ter se baseado na identificação ou no "reconhecimento dos traços peculiares de cada uma das culturas que produzem seus respectivos discursos, traços esses que se confundem com os traços de cada cultura" (Iasbeck, 2009, p. 18). Em outras palavras, a manipulação do conceito contribuiu para transformar o não-texto em texto, ao utilizar forças contrárias inicialmente potencializadoras da criatividade, também compreendida como modo de resolver problemas (Novaes, 1972).

Assim o conceito empregado na retórica da organização bancária que tinha como objetivo solucionar problemas de comunicação tornou-se recurso criativo de uma estratégia adversa. Isso porque, naquele momento, o discurso opositor foi apresentado como novidade, característica relacionada à efemeridade (Roman, 2009). Entretanto, o período curto e os meios - oficiais e não oficiais - de veiculação da mensagem contrária foram suficientes para modificar a estratégia e até mesmo suspender a veiculação de peças da campanha, cuja efemeridade foi provocada pela ação de lobby. Esta pode ser considerada criativa por seu caráter subversivo em relação ao anunciante, embora adaptado em relação à oposição ao governo; e por sua ambígua similaridade com uma comunicação informal ou por sua característica de rumor. Não chega a ser uma comunicação informal de fato, por não ter sido produzida espontaneamente. Entretanto, pode ter sua eficácia baseada também em seu caráter rumorístico, pois Roman (2009), baseado em Restrepo e Angulo (1992), aponta ser o rumor eficaz porque "se refere à realidade, mas não tem compromisso com ela, chegando a revertê-la” (Roman, 2009, p. 134); e por ser capaz de se difundir rapidamente.

Dessa forma, a cultura organizacional do banco foi colocada em questionamento diante da opinião pública e o discurso do opositor caracterizou-se como um não-texto, cujo sentido se concretizou no contexto externo à organização, onde se tornou vitorioso diante da chance de transformar a mensagem central da campanha praticamente numa ameaça à democracia. A vulnerabilidade do 
anunciante diante do conteúdo de sua própria comunicação vai ao encontro do quarto modelo de comunicação organizacional de Goodall Jr., Eisenberg e Trethewey (2010), que "apresenta a comunicação do ponto de vista do equilíbrio entre a criatividade e sujeição” (Scroferneker, 2006, p. 51) e considera interações sociais e jogos de poder. Em nossa abordagem, os dois últimos fenômenos são regidos pela cultura dentro da qual a organização negocia significados para manutenção do status quo ou para promover alguma mudança e assim caracterizar-se como criativa.

Cabe ressaltar que não está entre nossos propósitos abordar a fundamentação da acusação proferida pelo referido político e veementemente negada pelo então presidente da República, pelo anunciante e pela agência de publicidade. $\mathrm{O}$ mesmo se aplica à consideração do possível envolvimento maior de interesses particulares do que em mudanças favoráveis à população à qual ambas as organizações devem prestar contas. Entretanto, podemos afirmar que o resultado foi favorável ao opositor no sentido de, diante do risco de comprometimento da imagem institucional, a veiculação da campanha ter sido bastante modificada. Essa consequência também denota a criatividade dos envolvidos com o planejamento e a produção da campanha, que se mostraram flexíveis e, na concepção de Bueno (2009), capazes de buscar alternativas para solucionar problemas inesperados e mudar a estratégia diante de uma adversidade.

Foi possível observar o poder de um quase rumor externo diante de um discurso organizacional (Roman, 2009) e, do ponto de vista do opositor, como estratégia de expressão de posicionamento e enfrentamento de gestores não apenas da organização anunciante, mas do governo federal como um todo. Sob esse ponto de vista, o lobby característico da ação opositora também pode ser considerado criativo por constituir um espaço de liberdade e questionamento de um discurso oficial e do modo como foram empregados valores estabelecidos. Soma-se a isso o fato de a acusação ter feito emergirem novos significados para um mesmo texto.

Do lado da organização atacada, funcionou também a "symbolic boundary spanning" (Halliday, 2009, p. 40) ou "simbólica das fronteiras organizacionais, [que] é um mecanismo de adaptação para manter a organização em sintonia com os ambientes com os quais interage", procurando gerir inclusive a troca de significados entre organização e contexto externo, em benefício próprio. Os gestores tanto da organização, quanto da comunicação conhecem os custos da perda de status de um banco que, como outros, incluiu responsabilidade social entre seus objetivos organizacionais, mas encontrou limite na mesma pluralidade fundamentadora da retórica de uma propaganda.

Portanto, o discurso oportunista, embora inconveniente em relação ao oficial, teve êxito decorrente também do fato de, diferentemente de contextos abordados por Roman (2009), ter surgido e se legitimado no ambiente externo à organização. E, embora houvesse margem para outra negociação de significados, 
a forma de torná-la favorável seria complexa e o banco não quis levar adiante aquela retórica sem pelo menos reformá-la. Tal comportamento valida considerações sobre o fato de o discurso organizacional estar mais voltado para "fomentar entendimento e honrar o pacto implícito de confiabilidade entre retor e públicos", segundo Halliday (2009, p. 46) do que para fins persuasivos. Entretanto, a própria autora considera a importância da argumentação no estabelecimento de laços de confiança, embora não considere o fato de os objetivos não estarem separados nem mesmo em propagandas institucionais, quando se visa a resultados em médio e longo prazo, como os refletidos na imagem institucional; e também resultados tangíveis, como número de clientes.

Independentemente de qual das duas fosse a intenção primordial expressa pela propaganda, a organização não quis aguardar os possíveis resultados da continuidade do lobby opositor, tanto em nível de linguagem quanto em nível político ou eleitoral. Isso porque a ação opositora fez o conceito "Decida pelo três” colocar em risco a identidade institucional, pois, se a relacionarmos com identificação ou empatia, "só há identidade quando a imagem convive harmoniosamente com as intenções estratégicas do discurso institucional” (Iasbeck, 2009 , p. 28). A vulnerabilidade fez a organização anunciante optar pelo redirecionamento de seu discurso e de estratégias correlacionadas. Essas medidas constituem ações de comunicação reparadoras, protetoras ou mesmo revigorantes de sua imagem diante de diferentes públicos, como aquela gestão do governo, a oposição, os funcionários e clientes do banco e os cidadãos brasileiros espectadores do jogo retórico vencido por uma estratégia de lobby.

\section{CONSIDERAÇÕES FINAIS}

Nossa abordagem demonstrou que a criatividade empregada na estratégia de comunicação de uma organização encontrou limites na recepção de seu discurso e teve como oponente a "coparticipação dos públicos na modificação da situação retórica” (Halliday, 2009, p. 48). Comprovou também não haver criatividade ou sentido estratégico suficientes para controlar uma imagem institucional, sendo tal controle uma meta. Se mesmo no âmbito interno, supostamente mais fácil de gerenciar ou controlar, organizações diversas enfrentam desafios e procuram utilizar a comunicação favoravelmente aos seus objetivos, o âmbito externo tende a dificultar ainda mais o cumprimento da meta, considerando que "a linguagem sofre coações que não são inerentes a ela, mas aos grupos socialmente organizados que dela fazem uso” (Roman, 2009, p. 128).

A ponderação se relaciona com o caráter cultural que rege a linguagem e as interações sociais correlacionadas nos mais diferentes contextos intra e interorganizacionais e assim afeta a cultura organizacional do anunciante. E foi diante de tal caráter que a compreensão do fenômeno requereu uma abordagem sociossemiótica (Machado, 2003), mais voltada para conferir poder ao sentido do que sentido ao poder. Além disso, procurou ir além do quinto 
modelo de comunicação organizacional sugerido por Goodall Jr., Eisenberg e Trethewey (2010) para tratar as "organizações como espaços de diálogo" (Scroferneker, 2009) ou mesmo de tensões, tendo nosso exemplo também envolvido o contexto interorganizacional. Envolveu ainda um texto da linguagem da propaganda, que, como os demais, media tensões diversas, em princípio, entre organizações da mesma categoria e, em nosso exemplo, entre organizações bem diferentes por um lado, mas por outro integrantes - e nem sempre apoiadoras - de uma gestão do governo federal.

Tais considerações apontam a importância de gestores da comunicação organizacional serem criativos também no sentido de estarem prontos para lidar com diferentes posicionamentos diante de seus discursos. Isso porque imprevisíveis formas de recepção podem ser determinantes da significação de mensagens como as de propaganda e, ao envolverem outros agentes na construção de significados, podem conferir aos mesmos o título de criativos. Há, portanto, uma necessidade de conhecer bem os valores partilhados pelos públicos da organização. Tais valores, relacionados com emoções, crenças e, consequentemente, condutas morais, são capazes de direcionar a interpretação de mensagens, a ponto de o discurso de uma organização poder se voltar contra ela própria. Isso, entretanto, irá se concretizar se os gestores de sua comunicação não conseguirem corrigir a estratégia e assim evitar danos para sua imagem, tarefa para a qual devem estar preparados.

\section{REFERÊNCIAS}

ALENCAR, Eunice S. de; FLEITH, Denise de S. Criatividade: múltiplas perspectivas. 3. ed. Brasília: Editora UnB, 2003.

ANGELO, Saulo; MININI, Marcos; MOLIN, Renan. Decida pelo três. Cláudio Freire e Luciano Toaldo, dir. de criação. São Paulo: Margarida Flores e Filmes, 2007. DVD/NTSC, 3 min., color. son.

BAIN, Paul. G.; KASHIMA, Yoshihisa; HASLAM, Nick. Conceptual beliefs about human values and their implications: human nature beliefs predict value importance, value trade-offs, and responses to value-laden rhetoric. Journal of Personality, v. 91, n. 2, p. 351-367, 2006.

COSTA, Wilson Bueno da. A comunicação como inteligência empresarial competitiva. In: KUNSCH, Margarida M. Krohling (Org.). Comunicação organizacional - Vol. 1. Histórico, fundamentos e processos. São Paulo: Saraiva, 2009. p. 367-387.

DAVIES, Bronwyn; HARRE, Rom. Positioning: the discursive production of selves. Journal for the Theory of Social Behavior, $\mathrm{n}$. 20, v. 1, p. 43-63, 1997.

DOMENACH, Jean-Marie. A propaganda política. São Paulo: Difusão Europeia do Livro, 1955.

EISENBERG, Eric M.; GOODALL, Jr. H. Lloyd; TRETHEWEY, Angela. Organizational communication: balancing, creativity and constraint. 6. ed. New York: Bedfor / St Martin's Press, 2010.

HALL, Stuart. A identidade cultural na pós-modernidade. 10. ed. Rio de Janeiro: DP\&A, 1992.

GRACIOSOSO, Francisco. Propaganda institucional: nova arma estratégica da empresa. São Paulo: Atlas, 1995.

HALLIDAY, Tereza Lúcia. Discurso organizacional: uma abordagem retórica. In: $\mathrm{KUNSCH}$, Margarida M. Krohling (Org.). Comunicação organizacional - Vol. 2. Linguagem, gestão e perspectivas. São Paulo: Saraiva, 2009. p. 31-51.

IASBECK, Luiz Carlos Assis. Identidade organizacional e a construção dos discursos institucionais. In: KUNSCH, Margarida M. Krohling (Org.). Comunicação organizacional - Vol. 2. Linguagem, gestão e perspectivas. São Paulo: Saraiva, 2009. p. 07-29.

KUNSCH, Margarida M. Krohling. Percursos paradigmáticos e avanços epistemológicos nos estudos da comunicação organizacional. In: KUNSCH, Margarida M. Krohling (Org.). Comunicação organizacional - Vol. 1. São Paulo: Saraiva, 2009. p. 63-89. 
MACHADO, Irene. Escola de semiótica. São Paulo: Ateliê Editorial / Fapesp, 2003.

MOSCOVICI, Serge. 0 fenômeno das representações sociais: investigações em psicologia social. In: MOSCOVICI, Serge (Org.). Representações sociais. 2. ed. São Paulo: Vozes, 2003. p. 29-109.

NOVAES, Maria Eliana. Psicologia da criatividade. 2. ed. Petrópolis: Vozes, 1972.

RABAÇA, Carlos A.; BARBOSA, Gustavo G. Dicionário de comunicação. 2. ed. Rio de Janeiro: Campus, 2002.

REBOUL, Olivier. Introdução à retórica. Rio de Janeiro: Martins Fontes, 1996.

RESTREPO, J. Mariluz; ANGULO, Jaime Rubio. Intervenir en la organizacion. Santafé de Bogotá: Significantes de Papel Ediciones, 1995.

ROMAN, Artur Roberto. Organizações: um universo de discursos bem-ditos, mal-ditos e não-ditos. In: KUNSCH, Margarida M. Krohling (Org.). Comunicação organizacional - Vol. 2. Linguagem, gestão e perspectivas. São Paulo: Saraiva, 2009. p. 125-157.

ROSA, Alberto. Dramaturgical actuation and symbolic communication: or how beliefs make up reality. In: VALSINER, Jaan; ROSA, Alberto. Cambridge Handbook of socio-cultural psychology. Cambridge: CUP, 2007, p. 293-317.

SCINOCCA, Ana Paula; FILHO, Expedito. Heráclito e Suplicy discutem sobre campanha [do Banco Beta] no Senado. Disponível em: <http://www.romildo.com/blog/?p=1271>. Acesso em: 01 nov. 2010.

SCROFERNEKER, Cleusa M. A. Processos comunicacionais dos programas de qualidade e de certificações. In: KUNSCH, Margarida M. Krohling (Org.). Comunicação organizacional - Vol. 1. Histórico, fundamentos e processos. São Paulo: Saraiva, 2009. p. 195-216.

VELHO, Gilberto. Individualismo e cultura. 7. ed. Rio de janeiro: Zahar, 2004.

WEBER, Max. Economia e sociedade. 4. ed. Brasília: UnB, 1998.

Recebido em: 20.12.2010 / Aceito em: 12.05.2011 